Gut, 1978, 19, 377-383

\title{
Effect of codeine phosphate, Lomotil, and Isogel on ileostomy function
}

\author{
C. R. NEWTON \\ From the Research Department, St. Mark's Hospital, London
}

SUMMARY The effect on ileostomy function of codeine phosphate, Lomotil, or Isogel was tested in 20 subjects at home living a normal life, studied over two three-day periods on and off treatment. Codeine phosphate $60 \mathrm{mg}$ three times daily was associated with a reduction in the mean total weight of ileostomy output and the ileostomy outputs of water, sodium, and potassium $(\mathbf{P}<0.05)$. The proportion of faecal solids increased on codeine and the effluent appeared thicker but the output of faecal solids remained unchanged. Mean. faecal fat increased on codeine. The transit rate from mouth to stoma was slower in four of the five subjects on codeine and a further two subjects withdrew from the trial with temporary intestinal obstruction while on the drug. Lomotil two tablets three times daily was associated with a small and statistically not quite significant fall in the mean total weight of ileostomy output and the ileostomy output of water. Sodium and potassium outputs in the effluent fell on Lomotil $(P<0.05)$ but the other parameters remained unchanged. Isogel $15 \mathrm{ml}$ three times daily was associated with an increase in the mean total weight of ileostomy output and the ileostomy outputs of water, sodium, potassium, and faecal solids ( $P<0.01$ ). Although the effluent looked more viscid on Isogel, the proportion of faecal solids was unchanged. These results suggest that codeine phosphate has a beneficial effect on ileostomy function, reducing the loss of water and electrolytes, while Lomotil has a similar but less effective action in the dosage tested. By contrast, Isogel increases the ileostomy loss of water and electrolytes and will aggravate their depletion in patients with excessive fluid effluents. The increase in faecal fat associated with taking codeine phosphate suggests that it should be stopped before collecting specimens for faecal fat estimations.

There are about 10000 patients with an ileostomy in the British Isles and many of them will at some time complain of an excessive fluid effluent. In a study by Ritchie (1971), $3 \%$ of 371 ileostomists followed-up over a 12-year period required hospital admission for non-obstructive, non-infective ileostomy diarrhoea. This type of diarrhoea may be attributable to recurrent Crohn's disease, idiopathic ileitis (Thayer and Spiro, 1962), ileal resection (Nuguid et al., 1963; Hill et al., 1974), or lactose intolerance (Gudmand-Høyer and Jarnum, 1970), but often the cause is obscure and symptomatic treatment is all that can be offered. However, there is very little published data documenting the effect on ileostomy output of treatments commonly given for an excessive effluent. Kanaghinis et al. (1963) and Hill (1976) recorded reduction in ileostomy output in single patients on codeine phosphate and Tytgat

Received for publication 21 November 1977 and Huibregtse (1975) recorded reduction in ileostomy output in 20 subjects on Loperamide, an antidiarrhoeal agent chemically related to diphenoxylate.

This study was undertaken in 1972 to test the effect of codeine phosphate, Lomotil (diphenoxylate $2.5 \mathrm{mg}$ and atropine $0.025 \mathrm{mg}$ per tablet) and Isogel (Ispaghula husk) on ileostomy function in subjects at home, living a normal life.

\section{Method}

Ileostomists with a 'runniness' problem, who were willing to take part in the study, were sought through the Ileostomy Association. As most had tried codeine phosphate, Lomotil, or Isogel before, it was impossible to allot them to the three treatment groups in a random fashion, so they tested whichever treatment they preferred, each subject testing one treatment only. 
The study consisted of a five-day control period on no treatment and a five-day test period on the treatment chosen, each subject acting as his own control. Subjects were asked to eat their normal diet and to stop any treatments which might affect bowel function, other drugs being continued throughout the study. The first two days of each five-day period were for equilibration. During the next three days, subjects collected all their ileostomy output each 24 hours in polyethylene bags, carrying out a mouth-to-stoma transit study, using 20 radio-opaque polythene pellets as described by Hinton et al. (1969), on one of the days. During the test period, subjects took either codeine phosphate $60 \mathrm{mg}$ three times daily, half an hour before breakfast, lunch, and dinner; Lomotil two tablets three times daily at the same times; or Isogel $15 \mathrm{ml}$ (approximately $6 \mathrm{~g}$ ) three times daily just before these meals. They were asked to comment on the treatment tested and to report immediately any unpleasant symptoms during the study.

Subjects were asked their age, the year of construction of their ileostomy, and whether they had had colitis preoperatively. No other attempt was made to determine the type of colonic pathology except in two subjects whose ileostomy outputs exceeded $3 \mathrm{~kg} / 24$ hours during the control period, where the hospital notes were examined. Apparatus for the study was delivered to and collected from subjects' homes. Transit study collections of ileostomy effluent were radiographed to identify the pellets and each 24-hour collection was weighed, homogenised, and analysed for the proportion of faecal solids by drying to constant weight at $100^{\circ} \mathrm{C}$, sodium and potassium by flame photometry, and faecal fat by the method of van de Kamer et al. (1949).

Mean results were calculated for each subject for the three-day test and control periods and these means were compared and differences assessed by the paired Student's $t$ test for all subjects taking the same treatment. Effect on transit was assessed by comparing the number of hours taken for the passage of $20 \%, 50 \%$, and $80 \%$ of the pellets during test and control periods.

\section{Results}

Twenty subjects volunteered to take part in the study and 18 of these completed it successfully, five testing codeine phosphate, seven testing Lomotil, and six testing Isogel. The subjects' sex, age, time interval since ileostomy, current medications, and comments on the treatment tested are shown in Table 1. All had had their operation because of inflammatory bowel disease except subject 20 , who had had a proctocolectomy for multifocal carcinoma of the colon. Among the subjects who volunteered to test Lomotil were the two (14 and 15) whose total ileostomy outputs were 3136 and $3224 \mathrm{~g} / 24 \mathrm{~h}$ during the control period, compared with the range of 383 to $1335 \mathrm{~g} / 24 \mathrm{~h}$ for the other 16 subjects. Although the effect of Lomotil on these two subjects showed the same trends as on the other five testing it, because of the enormous difference in magnitude, their results were analysed separately. The results for total ileostomy output, proportion of faecal solids, weight of faecal solids, ileostomy output of sodium and faecal fat during test and control periods on the three treatments are shown in Figs 1 to 5 . The other results are summarised in Table 2.

\section{CODEINE PHOSPHATE}

The taking of codeine phosphate was associated with a significant fall in total ileostomy output and the ileostomy output of water, the proportion of faecal solids rising and the effluent appearing thicker while the weight of faecal solids remained unchanged. Codeine phosphate was also associated with a significant reduction in the ileostomy outputs of sodium and potassium without change in their concentrations. The output of faecal fat rose significantly (from 21 to $34 \mathrm{mM}$ or 6.1 to $9.6 \mathrm{~g} / 24 \mathrm{~h}$, $P<0.05)$ and in all subjects on codeine. In the mouth-to-stoma transit study, transit was slower on codeine in four of the five subjects and the average time taken for passage of $20 \%, 50 \%$, and $80 \%$ of the pellets was longer during the test period, but these changes were not statistically significant. Two other subjects had to stop the study on codeine because of temporary intestinal obstruction after two doses of $60 \mathrm{mg}$ and five doses of $30 \mathrm{mg}$, although neither had symptoms of intestinal obstruction before starting the study and both had average to large total ileostomy outputs during the control period (765 and $975 \mathrm{~g} / 24 \mathrm{~h}$ ). In both cases the obstruction relieved itself spontaneously some hours after stopping the drug.

\section{LOMOTIL}

In the five subjects considered here (9 to 13), the taking of Lomotil was associated with a small and statistically not quite significant fall in total ileostomy output and the ileostomy output of water, with no change in the output of faecal solids or their proportion in the effluent. Lomotil was, however, associated with a significant reduction in the ileostomy outputs of sodium and potassium without change in their concentrations. The output of faecal fat was unchanged on Lomotil and there was no consistent change in the pattern of transit. 
Table 1 Details of subjects, their current medications, and comments on treatment tested

\begin{tabular}{|c|c|c|c|c|c|}
\hline $\begin{array}{l}\text { Subject } \\
\text { no. }\end{array}$ & $\begin{array}{l}\text { Sex and } \\
\text { age }(y r)\end{array}$ & $\begin{array}{l}\text { Ileo. age } \\
\text { (yr) }\end{array}$ & $\begin{array}{l}\text { Rx for } G I \\
\text { tract-stopped* }\end{array}$ & $\begin{array}{l}\text { Other } R x- \\
\text { continued }\end{array}$ & Comments on $R x$ tested \\
\hline $\begin{array}{l}1 \\
2\end{array}$ & $\begin{array}{l}\text { M39 } \\
\text { M58 }\end{array}$ & $\begin{array}{l}8 \mathrm{~m} \\
8 \mathrm{~m}\end{array}$ & 二 & Chlorpropamide & $\begin{array}{l}\text { Codeine phosphate }(60 \mathrm{mg} t d s) \\
\text { On C no effect noted } \\
\text { On C felt bloated, IE too thick to come out of bag easily }\end{array}$ \\
\hline 3 & M58 & $2 \mathrm{~m}$ & C: $60 \mathrm{mg}$ qds & - & $\begin{array}{l}\text { Off } C \text { felt weak, unwell, very irritable, formication. Back to normal } \\
\text { on } C\end{array}$ \\
\hline 4 & F30 & 7 & C: $60 \mathrm{mg}$ tds & - & Off $\mathrm{C}$ felt weak, tired. Back to normal on $\mathrm{C}$ \\
\hline 5 & F44 & 3 & $\begin{array}{l}\text { C: } 30 \mathrm{mg} \text { tds } \\
\text { I: } 5 \mathrm{ml} \mathrm{od}\end{array}$ & - & Off C felt weak, tired, sleepy. Back to normal on C \\
\hline 6 & M51 & 17 & - & - & $\begin{array}{l}\text { On C felt weak, dizzy, vomited. C stopped after } 60 \mathrm{mg} \times 2 \text {. No IE for } \\
12 \mathrm{hr} \text {, then normal. Tested I instead }\end{array}$ \\
\hline 7 & M72 & 8 & - & - & On C vomited, abdo. distended, ileo. effluent watery. C stopped after \\
\hline 8 & M17 & 4 & C: $60 \mathrm{mg}$ tds & - & $\begin{array}{l}\text { Off C ileo. effluent watery, bag fell off after missing C } 60 \mathrm{mg} \times 2 \text {. } \\
\text { Study abandoned. Back to normal on C }\end{array}$ \\
\hline 9 & F58 & $7 \mathrm{~m}$ & - & $\begin{array}{l}\text { Thyroxine } \\
0.1 \mathrm{mg} \text { bd }\end{array}$ & $\begin{array}{l}\text { Lomotil }(2 \text { tablets } t d s) \\
\text { On } L \text { headache, no effect on IE noted }\end{array}$ \\
\hline 10 & F61 & 19 & $\begin{array}{l}\text { Cl tabs } \\
2 \text { tds }\end{array}$ & $\begin{array}{l}\text { Navidrex K } \\
1 \text { od } \\
\text { Indomethacin } \\
25 \text { mg tds } \\
\text { Vitamin B, C } \\
\text { tabs. } 2 \text { tds }\end{array}$ & On $L$ felt sleepy, no effect on IE noted \\
\hline 11 & M67 & 17 & - & - & On L no effect noted \\
\hline 12 & F62 & 3 & - & - & On $L$ no effect noted \\
\hline 13 & M62 & 3 & - & & On $L$ felt unwell, nauseated, no effect on IE noted \\
\hline 14 & F27 & $5 \mathrm{~m}$ & - & $\begin{array}{l}\text { Welldorm } \\
2 \text { nocte }\end{array}$ & On L felt unwell, faint, no effect on IE noted \\
\hline 15 & M47 & 12 & C: $30 \mathrm{mg}$ bd & - & $\begin{array}{l}\text { Off C felt weak, muscle cramps, IE more fluid. On L cramps disappeared, } \\
\text { IE same as on C } 30 \mathrm{mg} \text { bd }\end{array}$ \\
\hline 6 & M51 & 17 & - & - & Isogel $15 \mathrm{ml} \mathrm{tds}$ \\
\hline 16 & M37 & 5 & - & - & I unpalatable, IE more solid, less smell \\
\hline 17 & F51 & 19 & - & - & I unpalatable, felt full-up, no effect on IE noted \\
\hline 18 & M29 & 19 & - & - & I unpalatable, felt full-up, increased thirst, skin around stoma improved \\
\hline 19 & F54 & 19 & I. Oce & - & On I no effect noted \\
\hline & M35 & $5 \mathrm{~m}$ & - & - & I unpalatable, no effect noted \\
\hline
\end{tabular}

*C: codeine. I: Isogel. Cl: Celevac. L: Lomotil. Occ: occasionally. IE: ileostomy effluent.

CODEINE

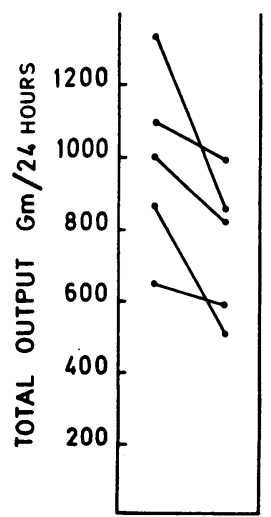

No Rx. Rx.

MEAN

DIFFERENCE

991755

SIGNIFICANCE

OF DIFF.

$-236$

$p<.05$
LOMOTIL

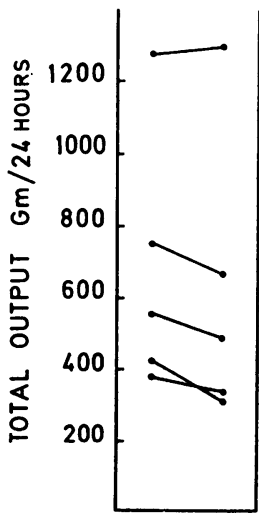

No Rx. Rx.

679622

$-57$

$.1<p>\cdot 05$
ISOGEL

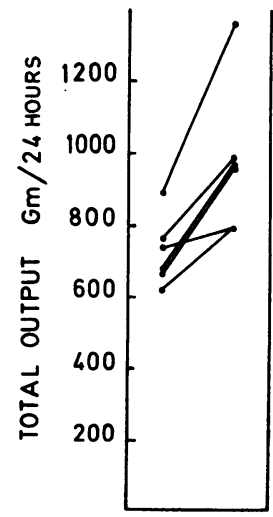

No Rx. Rx.

728978

$+250$

$p<.01$
Fig. 1 Total ileostomy output per 24 hours: mean results with differences on treatment and their significance. 

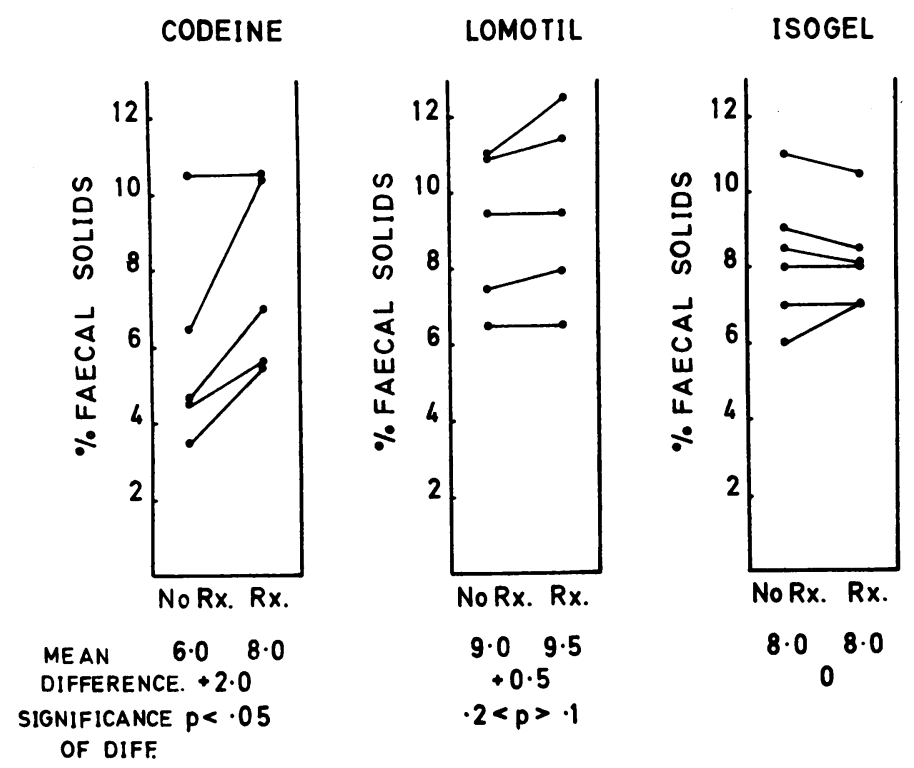

Fig. 2 Proportion of faecal solids in ileostomy effluent: mean results with differences on treatment and their significance.

CODEINE

LOMOTIL

ISOGEL

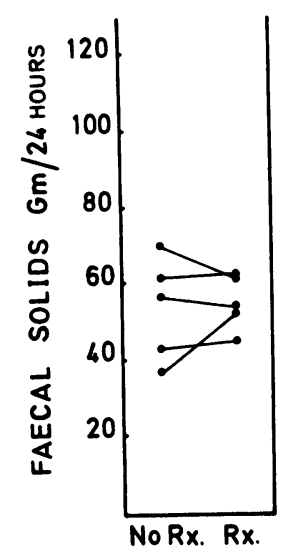

MEAN $54 \quad 55$

DIFFERENCE. +1

SIGNIFICANCE $p>.5$

OF DIFF.
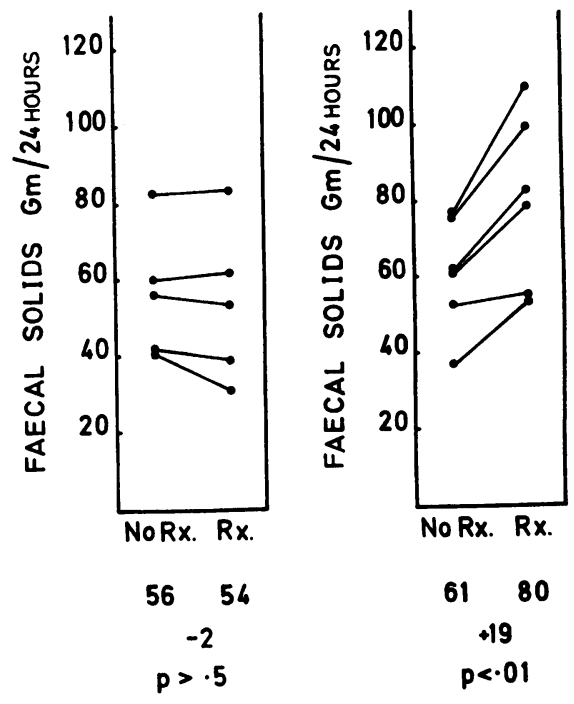

Fig. 3 Weight of faecal solids per 24 hours in ileostomy effluent: mean results with differences on treatment and their significance.
SOGEL

The taking of Isogel was associated with a significant increase in total ileostomy output and the ileostomy output of water. Although the effluent appeared more viscid on Isogel, the proportion of faecal solids remained unchanged. The mean weight of faecal solids increased by $19 \mathrm{~g} / 24 \mathrm{~h}$, compared with the $18 \mathrm{~g}$ Isogel that subjects were asked to take each day. Isogel was also associated with a significant increase in the ileostomy outputs of sodium and potassium without change in their concentrations. The output of faecal fat increased on Isogel in four of the six subjects, although this change did not reach statistical significance, and there was no consistent change in the pattern of transit.

TWO SUBJECTS WITH TOTAL ILEOSTOMY OUTPUTS EXCEEDING $3 \mathrm{~kg} / 24 \mathrm{~h}$

Both these subjects had had a total colectomy and 


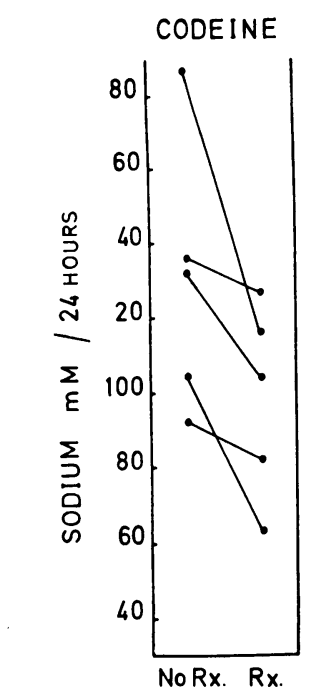

$$
\begin{aligned}
& \text { MEAN } 131 \quad 99 \\
& \text { DIFFERENCE. } \quad-32 \\
& \text { SIGNIFICANCE } \quad P<.05 \\
& \text { OF DIFF. }
\end{aligned}
$$
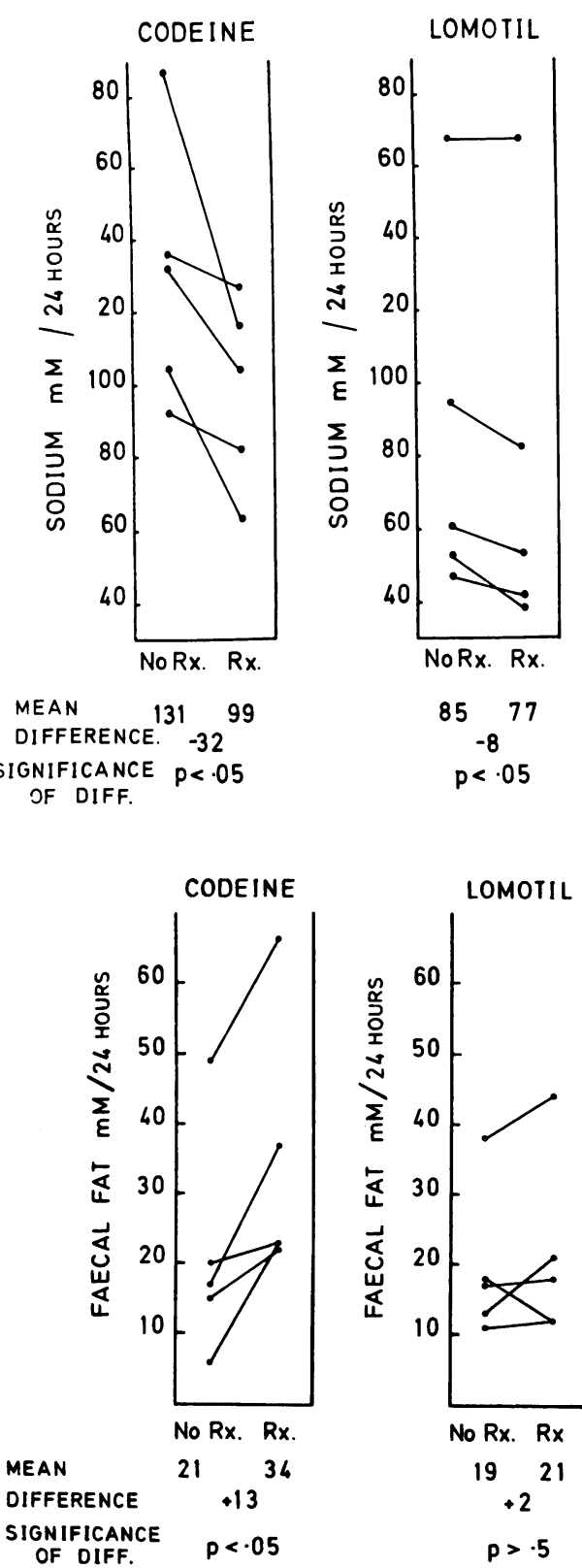

ISOGEL

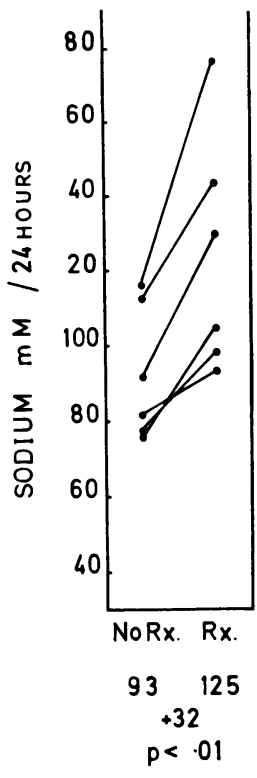

ISOGEL

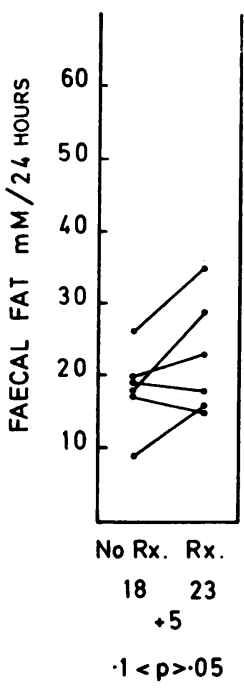

Fig. 4 Ileostomy output of sodium per 24 hours: mean results with differences on treatment and their significance.
Fig. 5 Ileostomy output of faecal fat per 24 hours: mean results with differences on treatment and their significance. ileostomy electively for ulcerative colitis and had then had an ileorectal anastomosis with initially reasonable bowel frequency (three to five bowel actions per day) and normal faecal fat excretion. Both subsequently had a complicated operative course, developing faecal fistulae through the abdominal wall, and now had a permanent ileostomy after excision of the rectum and several lengths of ileum. In subject 14 , the total length of terminal ileum resected was $115 \mathrm{~cm}$ and an excessive ileostomy effluent was noted from the time of the second resection which measured $100 \mathrm{~cm}$. Subject 15 had had three separate ileal resections with reanastomosis.

During the control period, both subjects produced an enormous output of water, solids, electrolytes, and faecal fat from the ileostomy. During the test period on Lomotil, there was a 10 to $20 \%$ reduction in the ileostomy output of water and 
Table 2 Analysis of ileostomy effluent and transit study: mean results with differences on treatment and their significance for determinations not depicted graphically

\begin{tabular}{|c|c|c|c|c|c|c|c|c|c|c|c|c|}
\hline \multirow{2}{*}{$\begin{array}{l}\text { Analysis of } \\
\text { ileo. effluent }\end{array}$} & \multicolumn{4}{|c|}{ Codeine phosphate } & \multicolumn{4}{|l|}{ Lomotil } & \multicolumn{4}{|l|}{ Isogel } \\
\hline & No $R x$ & $\boldsymbol{R} x$ & Diff. & $\begin{array}{l}\text { Sig. of } \\
\text { diff. }\end{array}$ & No $R x$ & $R x$ & Diff. & $\begin{array}{l}\text { Sig. of } \\
\text { diff. }\end{array}$ & No $R x$ & $R x$ & Diff. & $\begin{array}{l}\text { Sig. of } \\
\text { diff. }\end{array}$ \\
\hline $\begin{array}{l}\mathrm{H}_{2} \mathrm{O} \text { output } \\
(\mathrm{g} / 24 \mathrm{hr})\end{array}$ & $\begin{array}{l}937 \\
(5)^{*}\end{array}$ & 700 & -237 & $P<0.05$ & $\begin{array}{l}623 \\
(5)\end{array}$ & 568 & -55 & $0.1<P>0.05$ & $\begin{array}{l}668 \\
(6)\end{array}$ & 898 & +230 & $P<0.01$ \\
\hline $\begin{array}{l}\mathrm{Na}^{+} \text {conc. } \\
\text { (mM/kg) }\end{array}$ & 133 & 132 & -1 & $P>0.5$ & 123 & 122 & -1 & $P>0.5$ & 127 & 127 & $\mathbf{0}$ & - \\
\hline $\begin{array}{l}\mathrm{K}^{+} \text {output } \\
(\mathrm{mM} / 24 \mathrm{hr})\end{array}$ & $6 \cdot 8$ & $4 \cdot 1$ & $-2 \cdot 7$ & $P<0.05$ & $4 \cdot 2$ & $3 \cdot 8$ & -0.4 & $P<0.05$ & $4 \cdot 7$ & $6 \cdot 7$ & $+2 \cdot 0$ & $P<0.01$ \\
\hline $\begin{array}{l}\mathrm{K}^{+} \text {conc. } \\
(\mathrm{m} \mathbf{M} / \mathbf{k g})\end{array}$ & $7 \cdot 2$ & 5.6 & -1.6 & $P>0.1$ & 6.4 & 6.7 & $+0 \cdot 3$ & $\mathbf{P}>\mathbf{0} \cdot \mathbf{1}$ & 6.5 & 6.9 & +0.4 & $P>0.1$ \\
\hline \multicolumn{13}{|l|}{$\begin{array}{l}\text { Transit } \\
\text { study-time } \\
\text { (hr) for } \\
\% \text { of pellets }\end{array}$} \\
\hline & $\begin{array}{l}2 \cdot 8 \\
(5)\end{array}$ & $4 \cdot 4$ & +1.6 & $P>0.2$ & $\begin{array}{l}2 \cdot 8 \\
(5)\end{array}$ & $4 \cdot 2$ & $+1 \cdot 4$ & $P>0.5$ & $\begin{array}{l}3 \cdot 2 \\
(5)\end{array}$ & $4 \cdot 8$ & $+1 \cdot 6$ & $P>0.5$ \\
\hline $\begin{array}{l}50 \\
80\end{array}$ & $\begin{array}{l}3 \cdot 2 \\
4 \cdot 4\end{array}$ & $\begin{array}{l}4 \cdot 8 \\
6 \cdot 8\end{array}$ & $\begin{array}{l}+1.6 \\
+2.4\end{array}$ & $\begin{array}{l}P>0.1 \\
P>0.2\end{array}$ & $\begin{array}{l}5 \cdot 2 \\
6 \cdot 0\end{array}$ & $\begin{array}{l}4 \cdot 6 \\
5 \cdot 4\end{array}$ & $\begin{array}{l}-0.6 \\
-0.6\end{array}$ & $\begin{array}{l}P>0.5 \\
P>0.5\end{array}$ & $\begin{array}{l}4 \cdot 0 \\
6 \cdot 0\end{array}$ & $\begin{array}{l}4 \cdot 8 \\
5 \cdot 2\end{array}$ & $\begin{array}{l}+0.8 \\
-0.8\end{array}$ & $\begin{array}{l}P>0.5 \\
P>0.5\end{array}$ \\
\hline
\end{tabular}

*Number of subjects from which figures derived in parentheses.

electrolytes, although electrolyte concentrations were unchanged, the proportion of faecal solids increased only a little and the steatorrhoea persisted. Mouth-to-stoma transit was very rapid during the control period and changed little on Lomotil.

\section{Discussion}

This study suggests, as did the two cases previously described, that codeine phosphate reduces the ileostomy output of water and electrolytes, so increasing the proportion of faecal solids in the effluent and thickening its consistency. As it has been shown that there is some negative correlation between ileostomy output and transit time (Newton, 1972), it seems probable that codeine decreases the output of water and electrolytes by prolonging the time of their contact with the small intestinal mucosa and the slowing of mouth-to-stoma transit on codeine in this study is in line with this. The temporary intestinal obstruction experienced by two subjects while on the drug suggests that it should be given with some caution initially, as the extent of response may vary widely in different individuals. Codeine has also been shown to delay emptying of the biliary tract by causing constriction at the sphincter of Oddi (Butsch et al., 1936) and it is perhaps possible that a reduction in bile output may have contributed to the rise in faecal fat on codeine in this study. This rise suggests that codeine should be stopped before collecting specimens for faecal fat estimations in ileostomists and also presumably in patients with intact colons.
This study suggests that Lomotil is associated with similar but less marked changes in the ileostomy effluent than those seen with codeine. The mode of action of Lomotil, whose active ingredient, diphenoxylate, is structurally related to pethidine, is probably similar to that of codeine and morphine (Bárány and Jacobson, 1964). The small effect of Lomotil seen here was perhaps partly due to the dosage chosen, the six tablets given being somewhat less than the maximum daily maintenance dose of eight tablets recommended by the manufacturers. Further increase in Lomotil dosage is limited symptomatically by the presence of atropine $0.025 \mathrm{mg}$ per tablet added to discourage addiction so, although this study suggests that Lomotil may be of benefit to patients with an excessive ileostomy effluent, perhaps in higher dosage than tested here, the atropine present in its formulation may limit this to ineffective levels.

Isogel, a hydrophilic colloid prepared from Ispaghula husk and consisting mainly of hemicelluloses and mucilage, is an unabsorbable carbohydrate given to ileostomists to make their effluent more solid. In individuals with an intact colon, ingestion of hemicelluloses has been shown to increase the dry weight and the wet weight of the stools (Williams and Olmsted, 1936; Macy et al., 1943) with an increase in the small amount of water normally lost from the colon. This study shows that Isogel has a similar effect on the ileostomy effluent, increasing the ileostomy loss of water and electrolytes rather than taking up water which would otherwise have been excreted in a more fluid effluent. In patients with a large, fluid ileostomy output, the taking of Isogel 
will exacerbate water and electrolyte depletionlarge quantities of unabsorbable carbohydrate in normal foodstuffs should also probably be avoided in these circumstances. Isogel would therefore only seem to be indicated for ileostomists where a more viscid effluent is specifically desired, perhaps to reduce leakage between the stoma and the ileostomy bag, and should be avoided where there is danger of serious water and electrolyte deficiency.

The two subjects testing Lomitil, whose ileostomy outputs during the control period exceeded $3 \mathrm{~kg} / 24 \mathrm{~h}$, are further examples of the association of extensive ileal resection with excessive ileostomy output.

I am very grateful to the Ileostomy Association of Great Britain and Ireland and its members for making this study possible by their administrative help with organisation, their financial assistance with transport costs, and the co-operation of those who so kindly volunteered to test the treatments. I am also very grateful to Professor J. E. Lennard-Jones for his helpful advice and criticism.

\section{References}

Bárány, F., and Jacobson, B. (1964). Endoradiosonde study of propulsion and pressure activity induced by test meals, Prostigmine and diphenoxylate in the small intestine. Gut, 5, 90-95.

Butsch, W. L., McGowan, J. M., and Walters, W. (1936). Clinical studies on the influence of certain drugs in relation to biliary pain and to the variations in intrabili- ary pressure. Surgery, Gynecology, and Obstetrics, 63, 451-456.

Gudmand-Høyer, E., and Jarnum, S. (1970). Incidence and clinical significance of lactose malabsorption in ulcerative colitis and Crohn's disease. Gut, 11, 338-343.

Hill, G. L. (1976). Ileostomy: Surgery, Physiology, and Management. Grune and Stratton: New York.

Hill, G. L., Mair, W. S. J., and Goligher, J. C. (1974). Impairment of 'ileostomy adaptation' in patients after ileal resection. Gut, 15, 982-987.

Hinton, J. M., Lennard-Jones, J. E., and Young, A. C. (1969). A new method for studying gut transit times using radioopaque markers. Gut, 10, 842-847.

van de Kamer, J. H., ten Bokkel Huinink, H., and Weyers, H. A. (1949). Rapid method for the determination of fat in feces. Journal of Biological Chemistry, 177, 347-355.

Kanaghinis, T., Lubran, M., and Coghill, N. F. (1963). The composition of ileostomy fluid. Gut, 4, 322-338.

Macy, I. G., Hummel, F. C., and Shepherd, M. L. (1943). Value of complex carbohydrates in diets of normal children. American Journal of Diseases in Children, 65, 195-206.

Newton, C. R. (1972). Comparison of bowel function after colectomy and ileostomy or ileorectal anastomosis for inflammatory bowel disease (abstract). Gut, 13, 855 .

Nuguid, T. P., Bacon, H. E., and Boutwell, J. (1963). The ileostomy: its physical characteristics and chemical behaviour. Diseases of the Colon and Rectum, 6, 293-296.

Ritchie, J. K. (1971). Ileostomy and excisional surgery for chronic inflammatory disease of the colon: a survey of one hospital region. Part 1 . Results and complications of surgery. Gut, 12, 528-540.

Thayer, W. R., and Spiro, H. M. (1962). Ileitis after ileostomy: prestomal ileitis. Gastroenterology, 42, 547-554.

Tytgat, G. N., and Huibregtse, K. (1975). Loperamide and ileostomy output-placebo-controlled double-blind[crossover study. British Medical Journal, 2, 667.

Williams, R. D., and Olmsted, W. H. (1936). The effect of cellulose, hemicellulose and lignin on the weight of the stool: a contribution to the study of laxation in man. Journal of Nutrition, 11, 433-449. 